\title{
Association between HPV detection in swab samples and tissue specimens and ophthalmic pterygium recurrence
}

\author{
Aikaterini K. Chalkia ${ }^{1,2} \cdot$ Melpomeni Tseliou $^{3} \cdot$ Georgios Bontzos $^{2}$ (D) $\cdot$ Nikolaos G. Tsakalis $^{1,2}$. \\ Dimitrios A. Liakopoulos ${ }^{1,2}$. Styliani Blazaki ${ }^{1,2}$. Georgios Sourvinos ${ }^{4,3} \cdot$ Efstathios T. Detorakis $^{1,3}$
}

Received: 2 March 2021 / Revised: 19 May 2021 / Accepted: 31 May 2021 / Published online: 22 June 2021

(c) The Author(s), under exclusive licence to Springer-Verlag GmbH Germany, part of Springer Nature 2021

\begin{abstract}
Purpose To investigate the presence of HPV on the ocular surface after surgical excision of HPV infected pterygia and the possible correlation of HPV with pterygium postoperative recurrence.

Materials and methods Both exfoliative pterygium swab samples and respective tissue specimens were received and analyzed with real-time PCR for the detection of HPV-infected pterygia. In addition, swab samples from patients that had HPV-infected pterygia with no recurrence after 1 year of follow-up, as well as swab samples from patients with healthy conjunctiva, were analyzed.

Results Forty eyes with pterygium of 40 patients and 40 eyes with normal conjunctiva were included in the study. HPV virus was detected in the tissue specimens of 11 patients (27.5\%) and in the swabs of 9 patients (22.5\%). The HPV subtypes detected were $33,39,45,56,59,66$, and 68 . The swab test had sensitivity of $81.82 \%$ and $100 \%$ specificity. In $15(43 \%)$ patients, a bare sclera technique was used for pterygium removal and eleven of these patients showed recurrence of the disease. Surgical excision with use of autologous conjunctival graft was performed in twenty patients and five of them had recurrence. Patients with recurrent disease were 12.41 times more likely to have an HPV-infected pterygium $(p=0.031)$. Furthermore, from the $11 \mathrm{HPV}$ positive patients, six had no recurrence, 1 year after surgery. In five of them, a swab sample was taken from the site of the surgical excision 1 year after surgery and real-time PCR was negative for HPV presence.

Conclusion Persistence of HPV infection seems to be correlated with postoperative pterygium recurrence. Further investigation with the use of the minimally invasive proposed swab technique may contribute in the understanding of pterygium pathogenesis and in the development of a more efficient treatment planning.
\end{abstract}

Keywords HPV $\cdot$ Virus $\cdot$ Conjunctiva $\cdot$ Pterygium

\section{Key Message:}

- $\quad$ Patients with ophthalmic pterygium present high rates of pterygium recurrence after surgical treatment.

- $\quad$ HPV infection was highly correlated with disease recurrence.

- HPV was not detected in the conjunctiva one-year after successful resection of HPV infected pterygia.

Georgios Bontzos

gbontzos@hotmail.com

Extended author information available on the last page of the article

\section{Introduction}

Ophthalmic pterygium represents one of the most challenging ocular surface diseases. Although it has been thoroughly studied through the last 50 years, its pathogenesis 
still remains unclear, and its treatment is invasive and with a high probability of pterygium recurrence $[1,2]$. The development of this wing-shaped lesion that originates from the limbus and grows towards the center of the cornea has been strongly correlated with exposure to ultraviolet radiation. In fact, solar radiation seems to act as a trigger factor in a multifactorial pathway of pathogenesis, where genetically altered limbal epithelial stem cells cause Bowman's layer dissolution, epithelial-mesenchymal transition, and angiogenesis. Other factors that seem to play an important role in pterygium formation are genetic predisposition and exposure to viruses [3-5].

As pterygium growth can cause obscuration of the visual axes, irregular astigmatism, and ocular inflammation, its surgical excision is often mandatory. Numerous surgical excisional techniques have been proposed; however, even the most advanced may result in serious, often sight-threatening, complications as well as in high rates of postoperative disease recurrence [6]. Thus, the development of minimally invasive treatment techniques would be an important step in the management of pterygium, and this would require understanding of its exact pathogenetic mechanisms.

Recent studies have reported that human papillomavirus (HPV) may act as a possible co-factor in at least a subgroup of pterygia, and a non-invasive method of HPV detection by employing real-time PCR on ocular surface exfoliative cytology specimens has been proposed [7-10]. The purpose of the present study is to examine the effect of pterygium excision on the presence of HPV on the ocular surface as well as the possible role of HPV on pterygium postoperative recurrence with the use of a minimally invasive diagnostic technique.

\section{Materials and methods}

This prospective, case-control study was conducted at the University Hospital of Heraklion, Greece, after ethical approval (registry number: 16440/21-11-2014), according to the ethical principles of the Declaration of Helsinki, by the Institutional Review Board of the University General Hospital of Heraklion.

Patients that were candidates for pterygium surgical excision were enrolled in our study. Recruitment requirements included the following criteria: (1) patients 18 years old or older, (2) presence of primary or recurrent, unilateral ophthalmic pterygium invading the cornea for $2-5 \mathrm{~mm}$, and (3) absence of other ocular or systemic pathology that could affect the results of the study or would preclude the participation for safety reasons. Patients with familial occurrence of pterygium were not excluded, as hereditary predisposition of pterygium has been proposed in different studies, but the mode of inheritance still remains unclear [2]. Moreover, patients with normal conjunctiva, age above 18 years old and absence of other ocular or systemic pathology that could affect the results of the study or would preclude the induction for safety reasons, were enrolled as control group. All patients received verbal and written description of the protocol and signed an informed consent form. A detailed medical chart was filled in for each patient, including demographic data (age, gender, profession, and place of living during the last 20 years), ophthalmic and systemic medical history, family ophthalmic history, topical and systemic medications, previous pterygium surgical excisions, and number of recurrences. The ophthalmic examination included measurement of best-corrected visual acuity (BCVA) with standard Snellen eye charts, slit lamp bio-microscopy, fundoscopy, measurement of intraocular pressure, and pterygium size (in $\mathrm{mm}$ covering the corneal surface). All pterygia were then photographed (Table 1).

Exfoliative cytology samples were collected as follows: after topical instillation of anesthetic eye drops, a sterile cotton swab was rolled over the pterygium surface (pterygium group) or over the normal nasal conjunctiva (control group), repeatedly in order to collect an adequate quantity of exfoliated material and then stored in appropriate sterile transport device containing Stuart transport medium (Meus s.r.l., Piove di Sacco, Italy) (Fig. 1).

Subsequently, pterygia were surgically removed. Procedures were performed under topical anesthesia by two experienced surgeons [ET (4 eyes) and AC (36 eyes)], and a tissue specimen from the excised pterygium was also collected in an appropriate sterile transport device (F.L. Medical s.r.l., Torreglia, Italy) for real-time PCR analysis. An incisional

Table 1 Demographics of patients that completed a 12-month followup period

\begin{tabular}{|c|c|c|c|}
\hline Variable & $\begin{array}{l}\text { No HPV-DNA } \\
\text { detection }(n=24)\end{array}$ & $\begin{array}{l}\text { HPV-DNA in tissue } \\
\text { specimen }(n=11)\end{array}$ & $\mathrm{P}$ value \\
\hline \multicolumn{4}{|c|}{ Patient characteristics, no. (\%) } \\
\hline Sex: Male & $19(79.2)$ & $7(63.6)$ & \\
\hline Female & $5(20.8)$ & $4(36.4)$ & $0.086^{\dagger}$ \\
\hline Sunlight exposure & $20(83.3)$ & $11(100)$ & n.s. $*$ \\
\hline Family history & $5(20.8)$ & $4(36.4)$ & n.s. ${ }^{*}$ \\
\hline Duration $>10 \mathrm{y}$ & $7(24.13)$ & $3(27.3)$ & n.s. $*$ \\
\hline Recurrent disease & $10(41.6)$ & $6(54.5)$ & n.s \\
\hline \multicolumn{4}{|c|}{ Population characteristics, mean (SD) } \\
\hline Age (years) & $65.5(13.4)$ & $64.4(11.4)$ & n.s. ${ }^{\S}$ \\
\hline $\begin{array}{l}\text { Pterygium Size } \\
(\mathrm{mm}) \text {, mean } \\
(\mathrm{SD})\end{array}$ & $3.03(0.93)$ & $3.01(0.89)$ & n.s. ${ }^{\S}$ \\
\hline
\end{tabular}

\footnotetext{
*Fischer's exact test

Chi-square test

${ }^{\S}$ Independent samples t-test

n.s. non-significant result
} 


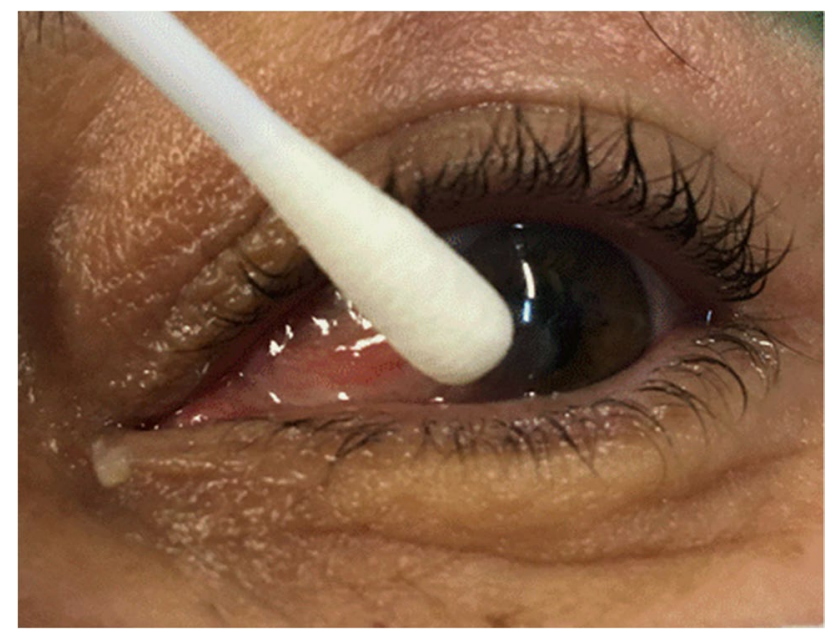

Fig. 1 Swab collection from pterygium surface

biopsy was obtained from all surgically excised pterygium specimens, and standard histopathological examination was performed in all cases in order to confirm diagnosis and exclude other pathology. All samples harvested for PCR analysis were stored at $-80{ }^{\circ} \mathrm{C}$ at the Laboratory of Molecular Virology of the University of Crete until DNA extraction.

For the DNA extraction from the swab samples, an appropriate DNA extraction kit was used and processed as per manufacturer's recommendations (Thermo Fisher Scientific Inc., USA). DNA isolation from tissue samples was performed by employing an appropriate kit (Macherey-Nagel $\mathrm{GmbH} \&$ Co. KG).

Real-time PCR was conducted with Mx3000P real-time PCR thermal cycler using software version 4.1 (Stratagene, La Jolla, CA, USA). PCR analysis of the swab samples preceded the analysis of tissues specimen to eliminate bias.

The presence of HPV in the tissue samples was detected using the general primers GP5 + and GP6 +, which target the $\mathrm{L} 1$ region of the viral genome using SYBR ${ }^{\circ}$ Green I dye. DNA was amplified in a final volume of $20 \mu \mathrm{l}$ containing $2 \times$ Maxima SYBR Green/ROX qPCR Master Mix (Thermo Fisher Scientific Inc., USA) and $300 \mathrm{~nm}$. of each primer. Samples underwent denaturation at $94{ }^{\circ} \mathrm{C}$ for $3 \mathrm{~min}$, 40 cycles of amplification, including denaturation at $94{ }^{\circ} \mathrm{C}$ for $30 \mathrm{~s}$, annealing at $44{ }^{\circ} \mathrm{C}$ for $1 \mathrm{~min}$ and elongation at $72{ }^{\circ} \mathrm{C}$ for $90 \mathrm{~s}$, followed by a melt curve analysis, in which the temperature was increased from 44 to $94{ }^{\circ} \mathrm{C}$ at a linear rate of $0.2{ }^{\circ} \mathrm{C} / \mathrm{s}$.

Genotyping of high- and intermediate-risk HPV genotypes was performed by real-time PCR using the kit HPV Genotypes 14 Real-TM Quant (Sacace Biotechnologies, Como, Italy, cat. no V67-100FRT) that offers detection of the 14 HPV genotypes: 16, 18, 31, 33, 35, 39, 45, 51, 52, $56,58,59,66$, and 68 . The PCR amplification included 1 cycle at $95{ }^{\circ} \mathrm{C}$ for $15 \mathrm{~min} ; 5$ cycles at $95{ }^{\circ} \mathrm{C}$ for $5 \mathrm{~s}$, at $60^{\circ} \mathrm{C}$ for $20 \mathrm{~s}$, at $72{ }^{\circ} \mathrm{C}$ for $15 \mathrm{~s}$; and 40 cycles at $95{ }^{\circ} \mathrm{C}$ for $5 \mathrm{~s}$, at $60{ }^{\circ} \mathrm{C}$ for $30 \mathrm{~s}$ and $72{ }^{\circ} \mathrm{C}$ for $15 \mathrm{~s}$. The quality control of the DNA samples was accomplished by checking for successful amplification of the beta-2-microglobulin, used as internal control (IC). A negative control (NC) buffer, verifying the lack of any contamination, provided by the kit was used during the real-time PCR analysis.

For the patients of the pterygium group, 1-year individualized follow-up was planned after surgery in order to check for disease relapse or postoperative complications. For all the HPV-positive patients that would complete the 12-month follow-up without recurrence, a new swab sample would be taken for HPV real-time PCR analysis, from the site of pterygium removal, according to the protocol described above.

\section{Statistical analysis}

Statistical analysis was performed with IBM SPSS software version 24 . Normality of continuous data was examined using the Shapiro-Wilk test. Distributions of quantitative variables are described as means ( \pm standard deviation). Qualitative variables were summarized by count and percentage. Cramer's V measures based on Pearson Chi-square tests were used to investigate the association between type of surgery and pterygium recurrence. Binary logistic regression analysis was performed to investigate factors associated with recurrency of the disease. Our model included parameters that could affect recurrency rates: patient age, gender, pterygium size, HPV detection, and excision technique.

\section{Results}

Forty eyes with pterygium of 40 patients and 40 eyes with normal conjunctiva were enrolled in the study. For the pterygium group, the median age was $64.23 \pm 12.65$ years (range 33-85). Thirty patients were male (75\%). All patients were Caucasians ( 35 were Greek, 2 were Bulgarian, 3 were Albanian). In all cases, histopathological examination confirmed the diagnosis of pterygium with no other coexisting ocular surface pathology. Ten patients (25\%) had a positive family ocular history, and 36 patients (90\%) reported chronic exposure to ultraviolet radiation.

No correlation was found between size of pterygium and sex $(\mathrm{p}=0.089)$, age $(\mathrm{p}=0.451)$, and family history $(\mathrm{p}=0.573)$. Statistically significant association was identified between the size of pterygium and recurrent disease $(\mathrm{r}=0.431, \mathrm{p}=0.006)$.

HPV virus was detected in the tissue specimens of 11 patients (27.5\%) and in the swabs of 9 patients (22.5\%), with no false-positive swab results. The HPV subtypes detected were $33,39,45,56,59,66$, and 68 . The sensitivity of the 
swab test was $81.82 \%$ (range 48.22-97.72), and the specificity was $100 \%$ (range $88.06-100$ ). The positive predictive value of the test was 100\% (range 86-100) and the negative predictive value was $93.55 \%$ (range 80.54-98.07).

Thirty five patients with pterygium (87.5\%) completed the 12-months follow-up. In 15 (43\%) of them, pterygium removal was performed with bare sclera excision and eleven of them $(73.3 \%)$ recurred (4/11 were HPV positive). Twenty patients (57\%) underwent surgical excision with use of autologous conjunctival graft, and five of them (25\%) recurred (2/5 were HPV positive). Pterygium size did not differ significantly between the two operation groups $(\mathrm{P}=0.54$, independent samples $\mathrm{t}$-test $)$.

On binary logistic regression, the presence of HPV was a significant predictor for disease recurrency $(\operatorname{Exp}[B]$ : $12.41 ; \mathrm{P}=0.031)$ as well as type of surgery $(\operatorname{Exp}[\mathrm{B}]: 0.245$; $\mathrm{P}=0.05)$.

Six HPV-pterygium-positive patients (had pterygium recurrence, 1 year after surgery. In five of the HPV-positive patients with no recurrent disease, a swab sample was taken from the site of the surgical excision, 1 year after surgery, and real-time PCR was negative for HPV presence.

The median age of the control group was $64.78 \pm 15$ (range 25-84). Twenty-four participants were male (60\%). No HPV infection was detected in the ocular surface in the control study pool. However, in 3 cases the quantity of DNA collected was insufficient for analysis.

\section{Discussion}

HPV infection has been associated with benign lesions, such as anogenital warts and laryngeal papillomatosis, and with the development of malignant lesions of the cervical, penile, anal, vaginal, and oropharyngeal region [11]. Moreover, HPV persistence after treatment has been correlated with recurrence of certain pathologies, such as sinonasal papillomas, head and neck squamous cell carcinomas, high-grade vaginal intraepithelial neoplasia, and cervical intraepithelial neoplasia of the cervix [12-16]. On the other hand, adjuvant HPV vaccination has been proposed as a preventive approach for recurrence of laryngeal papillomatosis [17].

Molecular assays that target in the identification of highrisk HPV DNA/RNA are nowadays considered the gold standard for the identification of the HPV in cervical disease. Real-time PCR represents a reliable method with good sensitivity and specificity for the detection of targeted HPV genotypes. In addition, real-time PCR permits detection of even minor quantities of nucleic acids, so it is ideal for both tissue and cellular specimens. Thus, real-time PCR assays have been implemented in the detection of high-risk HPVs in cervical specimens (Cobas ${ }^{\circledR}$, Abbott) in cervical cancer screening $[18,19]$.
Conjunctival swabs have been used in ophthalmology for the detection of viruses such as adenovirus, herpes simplex virus, and SARS-CoV-2 [20]. HPV has been widely accepted as a possible cofactor in the pathogenesis of pterygium $[7,8]$. In our study, in order to examine the effect of pterygium excision on the presence of HPV on the ocular surface, as well as the possible role of HPV in pterygium postoperative recurrence, we used real-time PCR in both swab samples and tissue specimens. The comparison of our results revealed excellent specificity and high sensitivity of the swab samples in the diagnosis of HPV-infected pterygia, rendering this technique a possible valuable tool not only in the understanding of pterygium pathogenesis but also in the treatment planning.

Currently, treatment of pterygium is based on its surgical resection. However, pterygium recurrence remains an important issue, and evidence indicates that growth of recurrent pterygia tends to be more prominent and aggressive. In addition, most recurrences seem to occur within the first year after surgery, and their excision presents higher rates of subsequent recurrence than primary pterygia [21].

Different factors have been correlated with pterygium recurrence, such as size and extension of pterygium in the cornea, increased vascularity, younger age, geographic location, and race [22, 23]. Ideal surgical treatment of pterygium should focus on minimal possibility of recurrence and complications, fast recovery, and good cosmetic results. For this reason, numerous surgical techniques have been developed, including the bare sclera technique, the use of autologous conjunctival grafts, limbal conjunctival grafts or amniotic membranes, and the "sliding flaps" technique [6, 24]. In addition, adjuvant therapies such as the use of $\beta$-irradiation, mitomycin C (MMC), 5-fluorouracil (5FU), thiotepa, antivascular endothelial growth factor (anti-VEGF) agents, cyclosporin A (CsA), and interferon (IFN) alpha-2b eye have been proposed in order to improve results regarding postsurgical recurrence, with though absence of consensus regarding the rates of both disease relapse and serious complications, such as corneal dellen, scleral necrosis and melting, cataract, or endophthalmitis [25]. Similarly, analysis of our results indicated that the size of pterygium and the type of surgery were significantly associated with disease relapse.

Moreover, in our study the presence of HPV was highly correlated with the possibility of pterygium recurrence, and in the subgroup of HPV-infected pterygia with successful resection after 1 year of follow-up, the virus hasn't been detected. To the best of our knowledge, this is the first study to report the potential correlation of HPV with the recurrence rate in pterygium with the use of a minimally invasive diagnostic technique. The aforementioned findings indicate that the minimally invasive detection of HPV in ophthalmic pterygia by the proposed method may be used as potential predictor of postoperative recurrence, leading in turn 
to more aggressive treatment planning for high-risk cases (including earlier or wider surgical excision, more extensive use of intra-operative anti-metabolites, such as mitomycin$\mathrm{C}$, closer postoperative monitoring for earlier detection of recurrences, or even the use of postoperative topical medications, such as interferon alfa- $2 b$, which has been successfully used in the treatment of HPV-related ocular surface disease [26]).

The correlation of HPV with postoperative recurrence and the absence of HPV in normal conjunctiva and in the subgroup of HPV-infected pterygia with successful resection also raise the query on whether HPV infection represents a cofactor in the pathogenesis of pterygia or whether the altered pterygium surface facilitates autoinoculation of HPV and subsequent postoperative disease relapse. In addition, as other viruses, such as HSV, EBV, and CMV, have been reported as possible risk factors for the development or the postoperative recurrence of pterygium, further analysis of their role in the pathogenesis and in the postoperative disease relapse is necessary $[5,27]$.

In conclusion, avoiding recurrence is the major challenge of pterygium treatment. The possibility of a reliable and minimally invasive technique that could permit the identification of HPV in pterygia and in the ocular surface after treatment may permit the evaluation of the efficacy of the current various surgical treatments and the development of more targeted therapies, the planning of the postoperative care, and the investigation of the role of HPV vaccination in the development and recurrence of the disease.

\section{References}

1. Reeh MJ (1971) Corneoscleral lamellar transplant for recurrent pterygium. Arch Ophthalmol 86(3):296-297

2. Bradley JC, Yang W, Bradley RH (2010) The science of pterygia. Br J Ophthalmol 94(7):815-820

3. Zhou WP, Zhu YF, Zhang B et al (2016) The role of ultraviolet radiation in the pathogenesis of pterygia. Mol Med Rep 14(1):3-15

4. Detorakis ET, Chrysochoou F, Paliobei V et al (2008) Evaluation of the acoustic function in pseudoexfoliation syndrome and exfoliation glaucoma: audiometric and tympanometry findings. Eur $\mathrm{J}$ Ophthalmol 18(1):71-76

5. Chalkia AK, Spandidos DA, Detorakis ET (2013) Viral involvement in the pathogenesis and clinical features of ophthalmic pterygium. Int J Mol Med 32(3):539-543

6. Hacıoğlu D, Erdöl H (2017) Developments and current approaches in the treatment of pterygium. Int Ophthalmol 37(4):1073-1081

7. Chalkia AK, Bontzos G, Spandidos DA et al (2019) Human papillomavirus infection and ocular surface disease. Int J Oncol 54(5):1503-1510

8. Piecyk-Sidor M, Polz-Dacewicz M, Zagórski Z et al (2009) Occurrence of human papillomavirus in pterygia. Acta Ophthalmol 87(8):890-895
9. Chalkia AK, Derdas S, Bontzos G et al (2018) Non-invasive detection of HPV DNA in exfoliative samples from ophthalmic pterygium: a feasibility study. Graefes Arch Clin Exp Ophthalmol 256(1):193-198

10. Chong PP, Tung CH, Rahman NA et al (2014) Prevalence and viral load of oncogenic human papillomavirus (HPV) in pterygia in multi-ethnic patients in the Malay Peninsula. Acta Ophthalmol 92(7):e569-e579

11. Ljubojevic S, Skerlev M (2014) HPV-associated diseases. Clin Dermatol 32(2):227-234

12. Vor der Holte AP, Fangk I et al (2020) Prognostic factors and risk factors for development and recurrence of sinonasal papillomas: potential role of different HPV subtypes. Eur Arch Otorhinolaryngol 277(3):767-75

13. Fakhry C, Blackford AL, Neuner G et al (2019) Association of oral human papillomavirus DNA persistence with cancer progression after primary treatment for oral cavity and oropharyngeal squamous cell carcinoma. JAMA Oncol 5(7):985-992

14. So KA, Lee IH, Kim TJ et al (2019) Risk factors of persistent HPV infection after treatment for high-grade squamous intraepithelial lesion. Arch Gynecol Obstet 299(1):223-227

15. Nagai $Y$, Maehama T, Asato T et al (2000) Persistence of human papillomavirus infection after therapeutic conization for CIN 3: is it an alarm for disease recurrence? Gynecol Oncol 79(2):294-299

16. Bogani G, Martinelli F, Ditto A et al (2017) Human papillomavirus (HPV) persistence and HPV 31 predict the risk of recurrence in high-grade vaginal intraepithelial neoplasia. Eur J Obstet Gynecol Reprod Biol 210:157-165

17. Nyirjesy S, Osmundson P, Matrka L (2020) Spontaneous regression of recurrent respiratory papillomatosis with hpv vaccination: a case study. J Voice. https://doi.org/10.1016/j.jvoice.2020.08.013

18. Hubbard RA (2003) Human papillomavirus testing methods. Arch Pathol Lab Med 127(8):940-945

19. Abreu AL, Souza RP, Gimenes F et al (2012) A review of methods for detect human Papillomavirus infection. Virol J 9(1):1-9

20. Sabage LE, Mazzo A, Sabage J, et al. (2021) Schirmer strip and conjunctival swab for viral detection on the ocular surface of adults: a scoping review. Available at Researchsquare. https:// doi.org/10.21203/rs.3.rs-113899/v4

21. Hirst LW, Sebban A, Chant D (1994) Pterygium recurrence time. Ophthalmology 101(4):755-758

22. Mahar PS, Manzar N (2013) Pterygium recurrence related to its size and corneal involvement. J Coll Phys Surg Pak 23(2):120

23. Han SB, Jeon HS, Kim M et al (2016) Risk factors for recurrence after pterygium surgery: an image analysis study. Cornea 35(8): 1097-1103

24. Janson BJ, Sikder S (2014) Surgical management of pterygium. Ocul Surf 12(2):112-119

25. Fonseca EC, Rocha EM, Arruda GV (2018) Comparison among adjuvant treatments for primary pterygium: a network meta-analysis. Br J Ophthalmol 102(6):748-756

26. Boehm MD, Huang AJ (2004) Treatment of recurrent corneal and conjunctival intraepithelial neoplasia with topical interferon alfa 2b. Ophthalmology 111(9):1755-1761

27. Rykov SO, Usenko KO, Mogilevskyy SI et al (2019) Relationship of the recurrence after pterygium surgery with the presence of HSV, EBV, CMV, HPV, and BRAFV600E mutation. J Ophthalmol (Ukraine) 1:486

Publisher's Note Springer Nature remains neutral with regard to jurisdictional claims in published maps and institutional affiliations. 


\section{Authors and Affiliations}

Aikaterini K. Chalkia ${ }^{1,2} \cdot$ Melpomeni Tseliou $^{3} \cdot$ Georgios Bontzos $^{2}(\mathbb{D})$. Nikolaos G. Tsakalis ${ }^{1,2}$.

Dimitrios A. Liakopoulos ${ }^{1,2}$. Styliani Blazaki ${ }^{1,2}$. Georgios Sourvinos ${ }^{4,3} \cdot$ Efstathios T. Detorakis $^{1,3}$

1 Department of Ophthalmology, University Hospital of Heraklion, Crete, Greece

4 Department of Virology, University Hospital of Heraklion, Crete, Greece

2 Faculty of Medicine, University of Crete, Heraklion, Greece

3 Laboratory of Clinical Virology, Faculty of Medicine, University of Crete, Heraklion, Greece 